\title{
Tapping the tree-ring archive for studying effects of resin extraction on the growth and climate sensitivity of Scots pine
}

\author{
Ernst van der Maaten*, Annemarie Mehl, Martin Wilmking and Marieke van der Maaten-Theunissen
}

\begin{abstract}
Background: In the German Democratic Republic (GDR), resin tapping in Scots pine (Pinus sylvestris L.) forests was a major economic activity, and resin-tapped stands are frequently found up until this day. In this study, we investigate how the mechanical damage caused by resin tapping affects the growth and climate sensitivity of Scots pine using a dendroecological approach.

Methods: Tree-ring samples were collected from resin-tapped and non-tapped trees in two forest areas in northeastern Germany, and tree-growth patterns were analyzed. For elucidating effects of resin tapping on the climate sensitivity of pine growth, climate-growth relationships and pointer years were studied.

Results: We observed that resin tapping positively affects tree growth at breast height, likely as wood formation is concentrated on the living part of the bole (i.e. after tapping there is no growth taking place on the tapping face due to the mechanical damage done to the cambium). We observed no differences in the climate sensitivity of tapped and non-tapped trees, nor in the occurrence of extreme growth responses.
\end{abstract}

Conclusion: Our results highlight that resin extraction is, apart from inflicting mechanical damage, not altering the sensitivity of Scots pine growth to climatic conditions.

Keywords: Climate-growth relationships, Dendroecology, Mechanical damage

\section{Background}

Resin tapping was a major economic activity in Scots pine (Pinus sylvestris L.) forests in the German Democratic Republic (GDR). For collecting resin, a system was used in which the outer layers of pine trees were diagonally incised over many years, leaving typical 'fish bone'-like patterns on the stem face behind (Fig. 1a). To protect themselves against (this mechanical) damage, pines produce resin: a highly viscous substance, rich in organic hydrocarbons. The resin was collected and processed to obtain turpentine and rosin. In turn, these substances were used as raw material in the production of glue, paint, shoe crème, plastics, and various other products (Stephan 1968). Although resin extraction was generally done about 10 years before final felling (to minimize negative impacts

\footnotetext{
* Correspondence: ernst.vandermaaten@uni-greifswald.de; ernst.vandermaaten@gmail.com

Institute of Botany and Landscape Ecology, University of Greifswald, Soldmannstr. 15, 17487 Greifswald, Germany
}

on forest yield), and despite the fact that resin extraction was completely abandoned after the reunification of Germany, resin-tapped Scots pine stands are still widespread and can be found throughout the former GDR today.

The mechanical damage inflicted by resin tapping likely affects tree growth. However, only few studies have analyzed effects of resin extraction on tree growth, while reporting contrasting findings. A study in Poland, for example, reports that resin tapping positively affects radial growth of Scots pine trees at breast height, but does not affect growth above the tapping face (Tomusiak and Magnuszewski 2009). Studies in Greece, Spain and China, on the other hand, indicate that pine growth is negatively impacted by resin extraction (Papadopoulos 2013; Génova et al. 2014; Chen et al. 2015) likely as a result of carbohydrates not being invested in tree growth but in excess resin production. Such differences may (partially) relate to differences in the autecology of the 

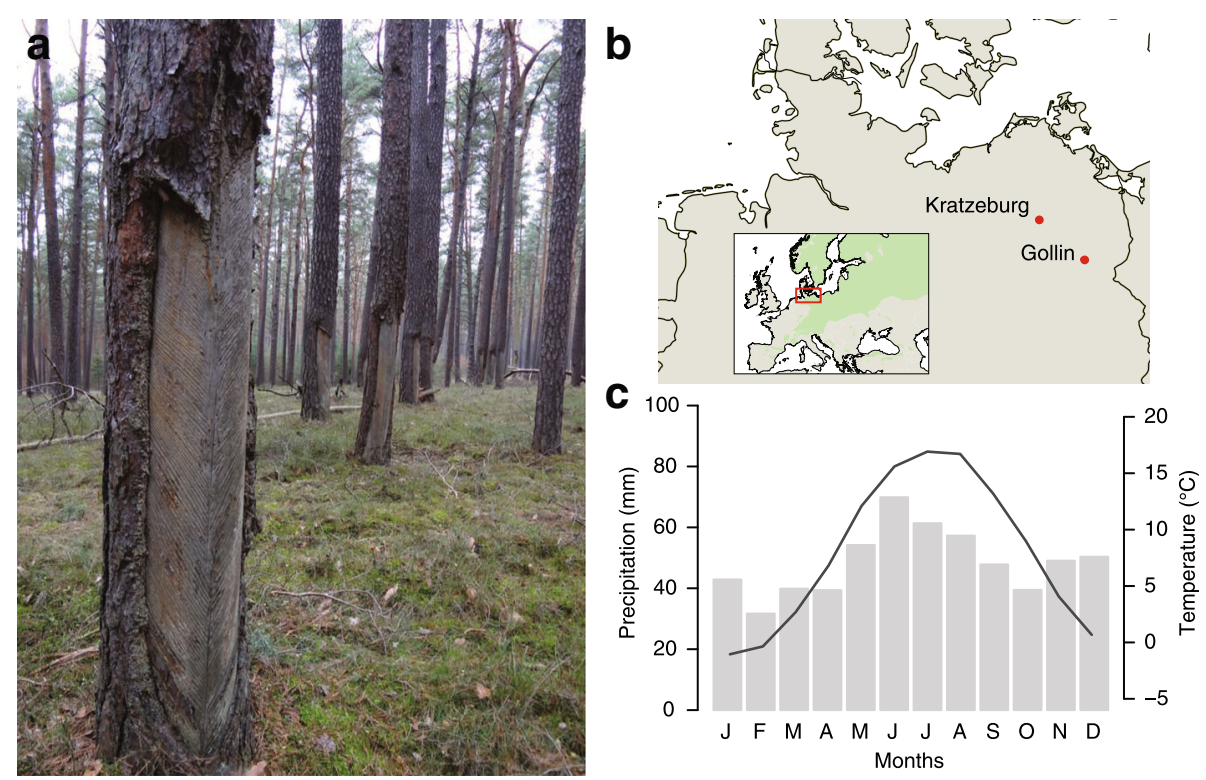

Fig. 1 (a) Resin-tapped Scots pine trees at Gollin. (b) Location of the studied forests with an inset map showing the study area within Europe as well as the approximate natural distribution of Scots pine in green (according to EUFORGEN 2017). (c) Climate diagram displaying mean monthly courses of air temperature (in ${ }^{\circ} \mathrm{C}$ ) and precipitation sums ( $\mathrm{mm}$ ) for site Kratzeburg (calculated over the climate normal period 1961-1990)

investigated pine species, as well as to differences in the applied resin extraction methods (Chen et al. 2015). Though studies on the effect of resin extraction on pine growth are already scarce, possible effects of resin tapping on the climate sensitivity of tree growth are even less studied (Génova et al. 2014). However, it might be hypothesized that the severe damage caused by resin tapping alters a trees' sensitivity to climatic stressors, for example, by making pine trees more susceptible to extreme weather events like droughts.

In this study, we "tap" the tree-ring archive to investigate how resin extraction affects the growth and climate sensitivity of Scots pine in two forest areas in northeastern Germany. More specifically, we compare tree growth and climatic responses for two neighboring resin-tapped and non-tapped Scots pine stands in both areas. Resin extraction is expected to result in smaller annual rings as carbohydrates are likely invested more in resin production rather than in wood formation. Further, we hypothesize to find differences in climate sensitivity of Scots pine in tapped and non-tapped stands with tapped trees being more prone to drought stress as part of their water transport system is damaged. This higher drought sensitivity is likely reflected both in climate-growth relationships over longer periods of time, as well as in growth responses of tapped pine trees in extreme years.

\section{Methods}

\section{Site description}

This study was conducted in two Scots pine forests in northeastern Germany, named Kratzeburg and Gollin after nearby villages (Fig. 1b). Kratzeburg forest $\left(53.4323^{\circ} \mathrm{N}, 12.9260^{\circ} \mathrm{E}\right.$, elevation: $\left.90 \mathrm{~m}\right)$ is located in Mecklenburg-Pommerania and lies within the borders of Müritz National Park, whereas Gollin forest $\left(53.0478^{\circ} \mathrm{N}, 13.6278^{\circ} \mathrm{E}\right.$, elevation: $\left.84 \mathrm{~m}\right)$ is situated further south in the federal state of Brandenburg. In both studied forests, even-aged Scots pine stands stock on well-drained sandy soils with relatively good nutritional status.

Site-specific monthly air temperature and precipitation data was obtained for the period 1900-2015 from a $1 \mathrm{~km} \times 1 \mathrm{~km}$ gridded climate surface of the German Weather Service (DWD). The climate at Kratzeburg and Gollin can be characterized as temperate humid with a mean annual air temperature of $8.0^{\circ} \mathrm{C}$ and $8.4{ }^{\circ} \mathrm{C}$, and with an annual precipitation sum of $583 \mathrm{~mm}$ and $568 \mathrm{~mm}$, respectively (calculated over the climate normal period 1961-1990). A climate diagram for Kratzeburg (Fig. 1c) shows that precipitation sums are highest in summer. Seasonal courses of air temperature and precipitation at Gollin (data not shown) are highly similar to Kratzeburg, though the climate is slightly more continental (i.e. higher temperature and lower precipitation amounts).

\section{Tree-ring data}

In both studied forests, we selected a neighboring resintapped and non-tapped Scots pine stand of comparable age (Table 1) growing under similar conditions. Per stand, we extracted two increment cores at breast height from 14 to 15 co-/dominant Scots pine trees. In the resin-tapped 
Table 1 Characteristics of the study trees

\begin{tabular}{|c|c|c|c|c|c|}
\hline & \multirow[b]{2}{*}{ Characteristic } & \multicolumn{2}{|l|}{ Kratzeburg } & \multicolumn{2}{|l|}{ Gollin } \\
\hline & & Tapped & Non-tapped & Tapped & Non-tapped \\
\hline \multirow[t]{4}{*}{ Raw data } & No. of trees & 15 & 14 & 15 & 15 \\
\hline & $\mathrm{DBH}(\mathrm{cm})$ & $51.2(3.8)$ & $44.6(5.9)$ & $39.2(5.0)$ & $41.4(3.9)$ \\
\hline & Height (m) & $25.6(1.5)$ & $24.6(1.9)$ & $26.1(1.9)$ & $28.2(1.2)$ \\
\hline & Segment length & $117(14)$ & $113(16)$ & $141(12)$ & $139(11)$ \\
\hline \multirow[t]{5}{*}{ Tree-ring indices } & glk & 0.68/0.69 & $0.63 / 0.68$ & $0.77 / 0.67$ & 0.68/0.68 \\
\hline & RBAR & $0.50 / 0.51$ & $0.43 / 0.45$ & $0.64 / 0.67$ & $0.48 / 0.58$ \\
\hline & MS & $0.17 / 0.18$ & $0.19 / 0.21$ & $0.22 / 0.23$ & $0.23 / 0.23$ \\
\hline & $A C$ & 0.09/0.09 & $-0.06 /-0.13$ & $-0.01 / 0.00$ & $-0.03 /-0.08$ \\
\hline & EPS & $0.94 / 0.94$ & $0.91 / 0.91$ & $0.96 / 0.97$ & 0.93/0.95 \\
\hline
\end{tabular}

Average values are presented for $D B H$ diameter breast height, height tree height, TRW tree-ring width, segment length number of measured tree rings per tree. Values between parentheses denote standard deviations. glk Gleichläufigkeit, RBAR inter-series correlation, MS mean sensitivity, AC first-order autocorrelation, EPS expressed-population signal. Statistics of tree-ring indices are presented for a 30-year period before and after resin extraction (before/after; see for periods Fig. 2)

stands, cores were taken from outside of the tapping face (i.e. from the living part of the stem). In addition, increment cores were extracted directly from the tapping face of three trees to date when resin extraction has been taking place. Sampling at Kratzeburg and Gollin was done in January and December 2016, respectively. After air-drying the collected increment cores, they were mounted on wooden holders, sanded with progressively finer grit sandpaper to highlight annual rings, and scanned with a highresolution flatbed scanner (Microtek ScanMaker 1000XL plus at $1200 \mathrm{dpi})$. We measured tree-ring widths (TRW) optically, and cross-dated the tree-ring series visually and statistically using the software package CooRecorder/ CDendro Version 8.1 (Cybis Elektronik and Data AB, Sweden). Ring-width series for individual trees were obtained by averaging the measurements from the two increment cores (taken from outside of the tapping area).

To highlight climate-induced growth fluctuations in the growth series, we detrended all series using a cubic smoothing spline with a 50\% frequency cut-off at 30 years. This detrending procedure effectively eliminates longer-term trends that may, for example, relate to forest management activities or tree ageing (Cook and Peters 1981). Indices were then calculated by dividing the observed by the predicted values. Site chronologies were constructed per stand by calculating a bi-weight robust mean of the index series of individual trees. To describe the characteristics and to assess the quality of the developed chronologies, we report the chronology statistics Gleichläufigkeit (glk), inter-series correlation (RBAR), mean sensitivity (MS), first-order autocorrelation (AC) and expressed population signal (EPS). Glk is the percentage of sign agreement in year-to-year ring-width changes, RBAR is the average correlation coefficient between series, MS is a within-series statistic that reflects the average relative difference in tree growth between consecutive years, $\mathrm{AC}$ is a measure of previous-year influence on current-year growth, and EPS is a statistic used to assess the adequacy of the replication in a site chronology (Wigley et al. 1984). Tree-ring chronologies were built and statistically evaluated using functions of the $d p l R$ package (Bunn 2008), developed for the $\mathrm{R}$ statistical software (R Development Core Team 2017).

\section{Statistical analyses}

To test for effects of resin extraction on absolute growth levels, we visually and statistically compared tree-growth patterns between two 30-year periods, before and after resin tapping using $t$-tests. Further, we examined the growth performance of resin-tapped trees in contrast to the performance of non-tapped trees. The 30-year periods before and after resin extraction were defined using the increment cores collected from the tapping face. Thereby, the post-periods started right after resin collection has stopped (i.e. 1984 at Kratzeburg and 1963 at Gollin), whereas the pre-periods ended 5 years earlier to account for the time lapse imposed by the applied resin extraction method.

For assessing effects of resin tapping on the climate sensitivity of Scots pine growth, we compared climategrowth relationships calculated over the aforementioned 30-year periods. Climate-growth relationships were calculated as bootstrapped correlation coefficients between site chronologies and monthly climate data, and identify climatic factors responsible for the observed growth variation. In the correlation analyses, we included monthly air temperature and precipitation data over a 16month window from June of the previous to September of the current year. Climate-growth relationships were established using the treeclim-package (Zang and Biondi 2015).

In addition to climate-growth relationships, which reflect average linear relationships between tree growth and climate, we studied growth responses of Scots pine to extreme events in a pointer-year analysis. Negative pointer 
years, which refer to years with remarkable growth depressions at the stand level (Schweingruber et al. 1990), were identified using the pointRes-package (van der Maaten-Theunissen et al. 2015). We defined pointer years using the normalization in a moving window method after Cropper (1979) with a window size of 5 years. Three intensity classes of pointer years (i.e. weak, strong and extreme) were considered after Neuwirth et al. (2007).

\section{Results}

Metadata and chronology statistics are provided in Table 1 . As indicated by the mean segment length, tree age is higher at Gollin than at Kratzeburg (mean segment length: $\sim 140$ versus $\sim 115$ years), but comparable between resin-tapped and non-tapped stands within both forests. Chronology statistics for the index chronologies are rather similar and no consistent differences in statistics were found between the period before and after resin extraction. High RBAR values, particularly for Gollin, together with high glk values indicate that pine trees show similar growth patterns within the individual stands. MS values around 0.2 point to moderately high year-to-year variability in tree growth, and $\mathrm{AC}$ values around zero to low "memory" effects (i.e. there is only a weak influence of previous-year upon current-year growth). Finally, EPS values beyond the commonly used threshold of 0.85 indicate that site chronologies can be considered reliable.
Mean TRW-chronologies for the resin-tapped and nontapped stands in Kratzeburg and Gollin are presented in Fig. 2. In the resin-tapped stands, tree growth significantly increased after resin extraction $(P$-values $<0.01)$. Whereas no significant differences in TRW between tapped and non-tapped stands were observed in the period before tapping $(P$-values $>0.1)$, differences were highly significant in the period thereafter $(P$-values $<0.01)$. The growthstimulating effect of resin tapping is, however, suggested to level off over time. At Gollin, for example, resin-tapped trees show only slightly higher growth levels $>30$ years after resin extraction compared to the non-tapped trees (Fig. 2b).

The established climate-growth relationships did not reveal consistent differences in climatic responses between resin-tapped and non-tapped trees, nor in the period before and after resin was extracted (Figs. 3 and 4). There are, however, differences in climate sensitivity of tree growth indicated between the two periods. At site Gollin, for example, summer drought is becoming a major growth-limiting factor in the post resin-extraction period, as indicated by significant negative and positive correlations with July temperature and precipitation, respectively. At site Kratzeburg, winter temperature signals (i.e. positive correlations with monthly temperature from previousyear December till current-year March) are particularly pronounced, whereas such signals are absent (period: 1930-1959) or weak (1964-1993) at Gollin.

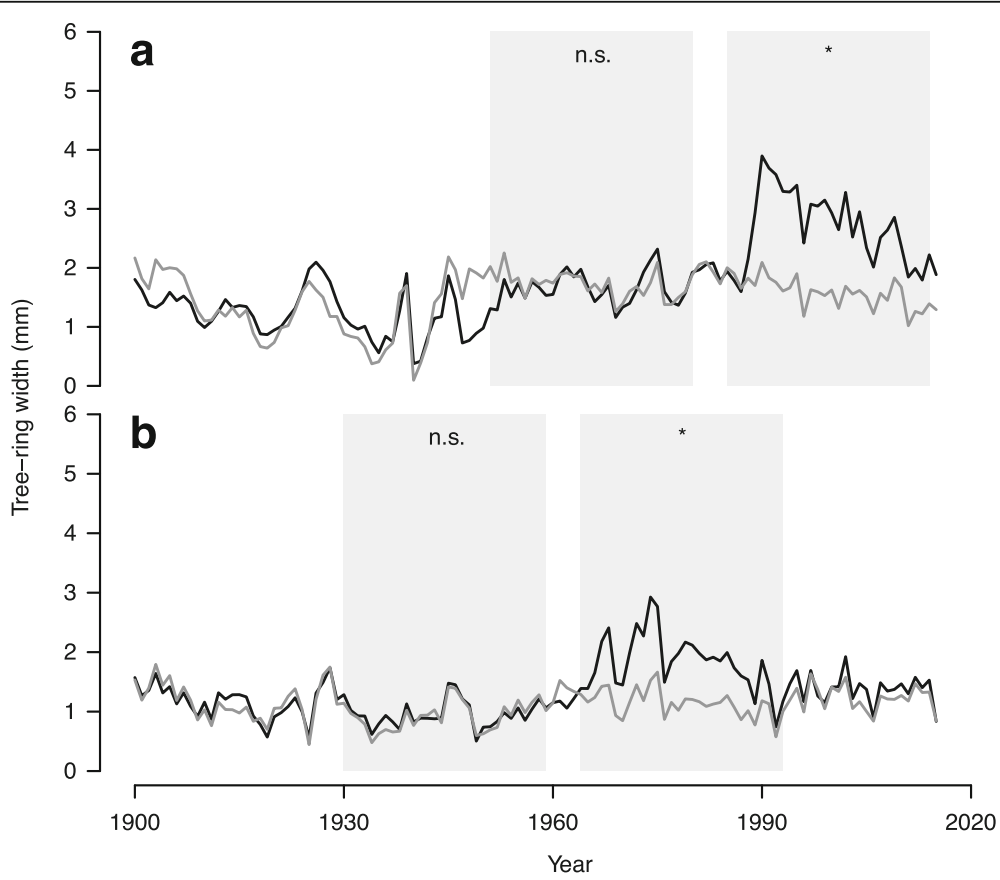

Fig. 2 Raw tree-ring chronologies for resin-tapped (black line) and non-tapped Scots pine stands (gray line) in (a) Kratzeburg and (b) Gollin, displayed from 1900 on. Gray shaded areas indicate 30-year periods before and after resin extraction took place. Growth performance of resin-tapped and non-tapped trees was compared for both periods using $t$-tests; asterisks denote significant $\left({ }^{*} P<0.05\right)$ and $n$.s. non-significant differences 


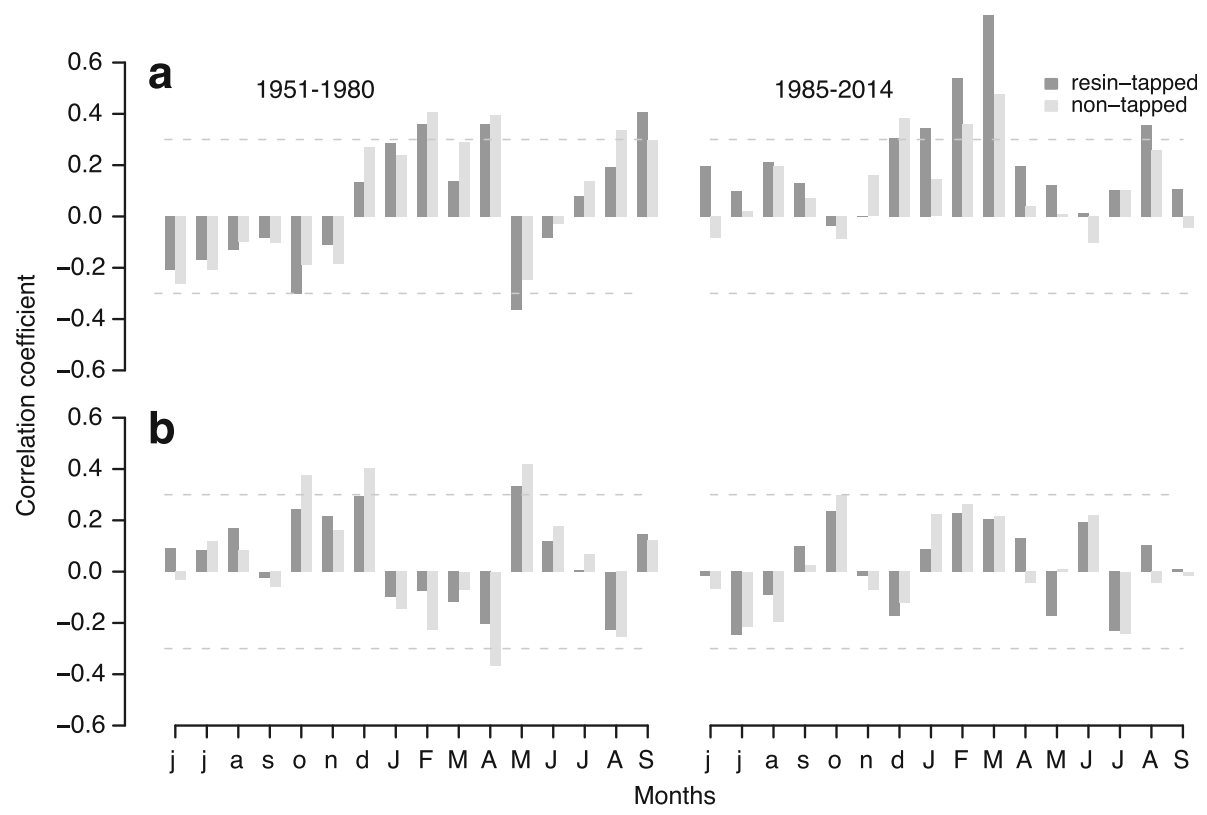

Fig. 3 Results of the bootstrapped correlation analysis between tree-growth indices and monthly (a) air temperature and (b) precipitation data for site Kratzeburg. Correlation coefficients are shown for the pre (left) and post (right) resin-extraction periods as highlighted in Fig. 2. Dark and light gray bars indicate correlations for tree-ring chronologies derived from resin-tapped and non-tapped trees. Months are abbreviated with lower- and uppercase letters for the previous- and current-year growing season, respectively

Similarly, the pointer-year analysis did not reveal differences in extreme growth responses between resin-tapped and non-tapped trees. Only one negative pointer year was detected in the period after resin extraction per studied forest. Irrespective whether trees were tapped or not, a strong negative pointer year was found at Kratzeburg in 1996, and at Gollin in 1992. The strong growth depressions in those years likely relate to cold winter and dry summer conditions in 1996 (Additional file 1: Figure S1), and drought in 1992 (Additional file 1: Figure S2).

\section{Discussion}

In this study, resin tapping in Scots pine was found to result in distinctively wider annual rings at breast height

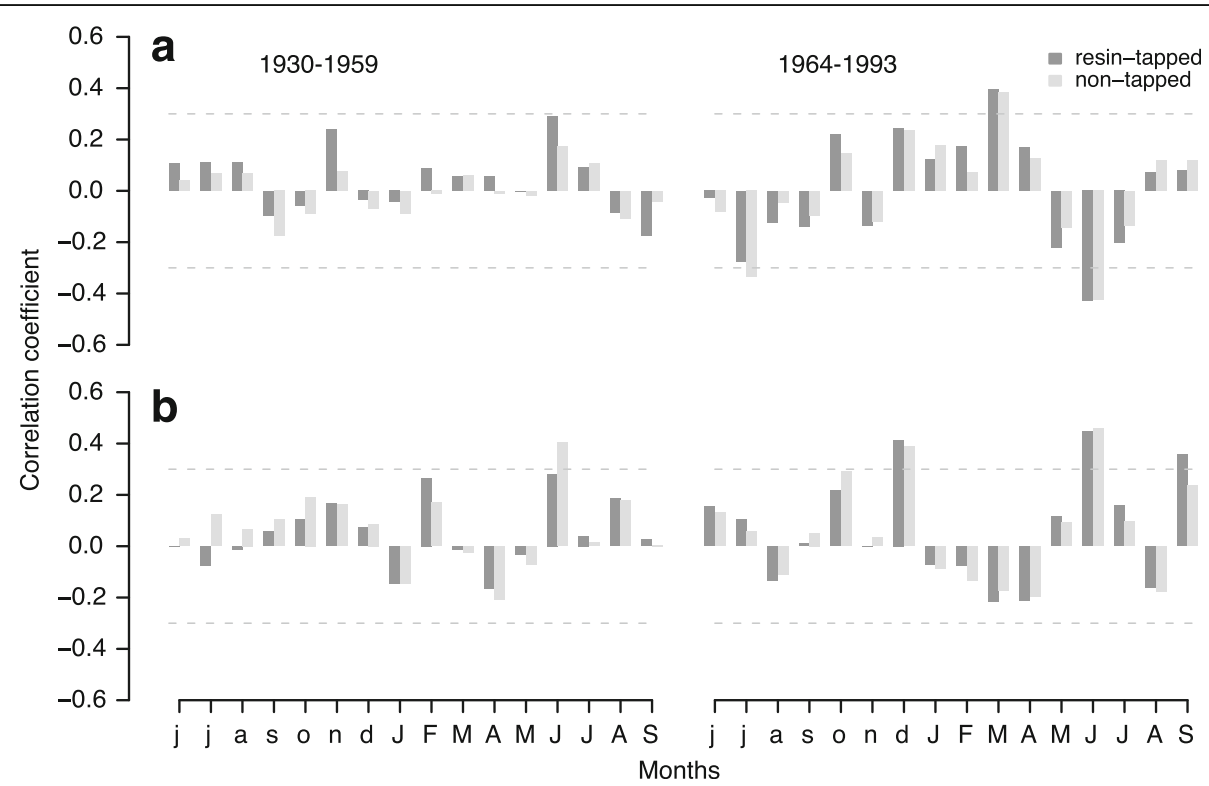

Fig. 4 Results of the bootstrapped correlation analysis between tree-growth indices and monthly (a) air temperature and (b) precipitation data for site Gollin. For further details, see the caption of Fig. 3 
(Fig. 2). For site Gollin, where resin tapping took place in the early 1960s, it could be observed that the growthstimulating effect of resin tapping levels off after about 30 years (Fig. 2b), whereas no such effects were observed for Kratzeburg (Fig. 2a) likely as a result of the more recent resin tapping. Similar to our results, Tomusiak and Magnuszewski (2009) observed increased growth at breast height after resin extraction in Scots pine in Poland. Above the tapping face (at a stem height of $3 \mathrm{~m}$ ), however, they did not observe growth stimulation. This difference in growth response is likely caused by the fact that wood formation is concentrated on the living part of the bole at breast height (i.e. after resin tapping, growth cannot take place anymore on the tapping face due to the mechanical damage done to the cambium), whereas tree rings are formed around the full stem circumference above the tapping face.

In contrast to our findings and those of Tomusiak and Magnuszewski (2009), but in line with our initial hypothesis, various other studies report a negative impact of resin extraction on the growth of various pine species (Papadopoulos 2013; Génova et al. 2014; Chen et al. 2015), which may relate to carbohydrates being invested in resin production rather than tree growth. Similarly, a study on growth responses of maritime pine (Pinus pinaster Ait.) following wounding by flash floods observed a decrease in tree-ring width close to the scars (Ballesteros et al. 2010). Possible explanations for the observed differences in tree growth after cambial damage include differences in the applied resin extraction methods (Chen et al. 2015), differences in the autecology of the investigated pine species, as well as differences in sampling design.

Whereas resin tapping significantly affected the absolute growth of Scots pine (Fig. 2), high-frequency growth fluctuations were found to be highly similar between resin-tapped and non-tapped trees. Consequently, hypothesized differences in climate-growth relationships (i.e. higher drought sensitivity of resin-tapped trees) could not be detected (Figs. 3 and 4). Similarly, Génova et al. (2014) found no indications that resin tapping affects the climate sensitivity of maritime pine growth in Spain.

Summer drought and winter temperature were identified as major growth-limiting factors for the growth of Scots pine (Figs. 3 and 4). At site Gollin, summer drought is suggested to become an increasingly important growth limiting factor, as expressed by a pronounced negative effect of June temperature and a concurrent positive effect of precipitation in the period 1964-1993 (Fig. 4). This effect likely relates to a warming trend observed over the second half of the twentieth century, which results in an increase of evaporative water losses. Winter temperature signals, on the other hand, were more pronounced at site Kratzeburg, especially for the period 1985-2014 (Fig. 3a).
Positive associations between tree growth and winter temperature are observed throughout the northern Central European lowlands (e.g., Elferts 2007; Pärn 2003; Koprowski et al. 2012). Physiologically, these positive associations may be explained by a positive carbon gain of Scots pine on warm winter days when the needles are not frozen (Chabot and Hicks 1982; Havranek and Tranquillini 1995). On the other hand, the maintenance of foliage throughout the winter may make pine more susceptible to winter desiccation or damage induced by frost, snow and ice (Pederson et al. 2004). Lastly, interactions between winter temperature, snow cover and fine-root mortality may contribute to the winter temperature sensitivity of Scots pine.

Differences in climate sensitivity of pine growth between the studied sites likely relate to specific site conditions. The higher drought sensitivity at Gollin, for example, may relate to the more continental climate with higher summer temperature extremes and lower precipitation sums. Drought stress is less pronounced at Kratzeburg; winter temperature is the major growth-limiting factor instead. The importance of drought and winter temperature for Scots pine growth at Gollin and Kratzeburg is furthermore reflected in the pointer-year analysis. At Kratzeburg, cold winter conditions in combination with a dry summer were suggested as possible cause for the negative pointer year in 1996 (Additional file 1: Figure S1), whereas drought is considered the main factor responsible for the growth depression observed at Gollin in 1992 (Additional file 1: Figure S2). Although climate-growth relationships for Kratzeburg and Gollin were calculated over different time windows (depending upon the period of resin extraction, cf. Fig. 2), climate response patterns indicate the same inter-site differences when calculated over identical periods (data not shown).

\section{Conclusion}

Resin extraction was found to stimulate the growth of Scots pine at breast height, whereas high-frequency growth fluctuations and climate-growth relationships of resin-tapped and non-tapped trees before and after tapping were shown to be highly similar. We also did not find any indication that resin tapping alters the growth response of Scots pine in years with extreme climatic conditions such as droughts. Resin extraction thus seems not to alter the susceptibility of pine to climatic stressors.

\section{Additional file}

Additional file 1: Figure S1. Monthly climate anomalies for air temperature (lines) and precipitation (bars) in 1996 relative to the 1961-1990 average for site Kratzeburg. Figure S2 Monthly climate anomalies in 1992 for site Gollin. (PDF 58 kb) 


\section{Acknowledgments}

We thank the Müritz National Park and the Forest District Reiersdorf for supporting our fieldwork. The comments of three anonymous reviewers were helpful to improve an earlier version of this manuscript.

\section{Funding}

This study profited from field equipment financed by the Eva Mayr-Stihl Foundation through a grant to EM and MMT. This study is a contribution to the Virtual Institute of Integrated Climate and Landscape Evolution Analysis -ICLEA(grant no. VH-VI-415) and to the Terrestrial Environmental Observatories project -TERENO- of the Helmholtz Association.

\section{Authors' contributions}

Conceived and designed the study: EM and MMT. Performed the field- and lab-work: EM, AM and MMT. Analyzed the data: EM and MMT. Wrote the manuscript: EM, AM, MW and MMT. All authors read and approved the final manuscript.

\section{Authors' information}

EM and MMT are postdoctoral forest growth researchers, with a special interest in studying effects of former land-use on the growth and vitality of todays' forests. Professor MW is a geo-ecologist working on the ecosystem dynamics of trees and shrubs in temperate and boreal regions, as well as the arctic tundra. AM is a graduate student that wrote her Bachelor thesis on effects of resin extraction on the growth of Scots pine in Müritz National Park. All authors are working at (or associated to) the Institute of Botany and Landscape Ecology at the University of Greifswald, Germany.

\section{Competing interests}

The authors declare that they have no competing interests.

\section{Field permits}

Research permissions to sample Scots pine trees were provided by the Müritz National Park and by the Forest District Reiersdorf.

Received: 18 February 2017 Accepted: 23 May 2017

Published online: 09 June 2017

\section{References}

Ballesteros JA, Stoffel M, Bodoque JM, Bollschweiler M, Díez-Herrero A (2010) Changes in wood anatomy in tree rings of Pinus pinaster ait. following wounding by flash floods. Tree-Ring Res 66:93-103

Bunn AG (2008) A dendrochronology program library in R (dpIR). Dendrochronologia 26:115-124

Chabot BF, Hicks DJ (1982) The ecology of leaf life spans. Annu Rev Ecol Syst 13:229-259

Chen F, Yuan YJ, Yu SL, Zhang TW (2015) Influence of climate warming and resin collection on the growth of Masson pine (Pinus massoniana) in a subtropical forest, southern China. Trees 29:1423-1430

Cook ER, Peters K (1981) The smoothing spline: a new approach to standardizing forest interior tree-ring width series for dendroclimatic studies. Tree-Ring Bull 41:45-53

Cropper JP (1979) Tree-ring skeleton plotting by computer. Tree-Ring Bull 39:47-59

Elferts D (2007) Scots pine pointer-years in northwestern Latvia and their relationship with climatic factors. Acta Univ Latv 723:163-170

EUFORGEN (2017) Distribution maps - Pinus sylvestris L. www.euforgen.org. Accessed 1 Feb 2017

Génova M, Caminero L, Dochao J (2014) Resin tapping in Pinus pinaster: effects on growth and response function to climate. Eur J For Res 133:323-333

Havranek M, Tranquillini W (1995) Physiological processes during their winter dormancy and their ecological significance. In: Smith WK, Hinkley TM (eds) Ecophysiology of coniferous forest. Academic, New York, pp 95-124

Koprowski M, Przybylak R, Zielski A, Pospieszynska A (2012) Tree rings of Scots pine (Pinus sylvestris $\mathrm{L}$.) as a source of information about past climate in northern Poland. Int J Biometeorol 56:1-10

Neuwirth B, Schweingruber FH, Winiger M (2007) Spatial patterns of central European pointer years from 1901 to 1971. Dendrochronologia 24:79-89

Papadopoulos AM (2013) Resin tapping history of an aleppo pine forest in Central Greece. Open For Sci J 6:50-53

Pärn H (2003) Radial growth response of Scots pine to climate under dust pollution in northeast Estonia. Wat Air Soil Poll 144:343-361
Pederson N, Cook ER, Jacoby GC, Peteet DM, Griffin KL (2004) The influence of winter temperatures on the annual radial growth of six northern range margin tree species. Dendrochronologia 22:7-29

R Development Core Team (2017) R: A language and environment for statistical computing. R Foundation for Statistical Computing, Vienna

Schweingruber FH, Eckstein D, Serre-Bachet F, Bräker OU (1990) Identification, presentation and interpretation of event years and pointer years in dendrochronology. Dendrochronologia 8:9-38

Stephan G (1968) Die Gewinnung des Harzes der Kiefer. Elbe-Druckerei, Wittenberg

Tomusiak R, Magnuszewski M (2009) Effect of resin tapping on radial increments of Scots pine (Pinus sylvestris L.). In: Kaczka R, Malik I, Owczarek P, Gärtner H, Helle G, Heinrich I (eds) TRACE - Tree Rings in Archaeology, Climatology and Ecology, Vol. 7: Proceedings of the DENDROSYMPOSIUM 2008, April 27th - 30th 2008. GFZ Potsdam, Scientific Technical Report STR 09/03, Potsdam, Zakopane, pp 151-157

van der Maaten-Theunissen M, van der Maaten E, Bouriaud O (2015) pointRes: an $R$ package to analyze pointer years and components of resilience. Dendrochronologia 35:34-38

Wigley TML, Briffa KR, Jones PD (1984) On the average value of correlated time-series, with applications in dendroclimatology and hydrometeorology. J Clim Appl Meteorol 23:201-213

Zang C, Biondi F (2015) treeclim: an R package for the numerical calibration of proxy—climate relationships. Ecography 38:431-436

\section{Submit your manuscript to a SpringerOpen ${ }^{\circ}$ journal and benefit from:}

- Convenient online submission

- Rigorous peer review

- Open access: articles freely available online

- High visibility within the field

- Retaining the copyright to your article

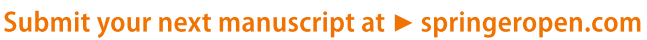

